\title{
The jamming mechanism of sand control screen for the montmorillonite inflation with the water
}

\author{
Fucheng Deng ${ }^{1} \cdot$ XueFeng Shen $^{2} \cdot$ Qimin Liang $^{3} \cdot$ Lihua Wang $^{1} \cdot$ Jie Wang $^{1} \cdot$ \\ Ziqiang Deng ${ }^{1} \cdot$ Jun Wei $^{1}$
}

Received: 25 June 2016/ Accepted: 22 January 2017/Published online: 2 March 2017

(C) The Author(s) 2017. This article is published with open access at Springerlink.com

\begin{abstract}
In the process of well completion with mechanical screen to control sand, once the water content of the reservoir increased, the montmorillonite in clay minerals would swell which combined with formation sand has an obvious effect on the plugging of screen pipe in production string. According to the prediction of water production of reservoir, shale expansion instrument was used to establish the relationship between the different water content and swelling properties of montmorillonites and combined with the clogging test of screen under different water content to evaluate the blocking effect of montmorillonite under different water content on the clogging of screen in the process of sand control. It can be found in the experiment that: (1) If the reservoir products water, the expansion height of two kinds of montmorillonites is similar when the water content of oil is less than $10 \%$ or more than $20 \%$, the expansion height of montmorillonites is large of which expansion rate can reach to $188 \%$ when the water content is between 10 and $20 \%$. (2) Through the simulation experiment of sand control, when the water content is 10 and $30 \%$, the screen blocking is the fastest, and the productivity index per meter is the lowest, the blockage rate is increased by nearly three times when the water content of oil is 0 . (3) The influence of concentration ratio of oil and water on the productivity index per meter of metal mesh screen is larger than the swelling of
\end{abstract}

Fucheng Deng

dengfucheng128@163.com

Yangtze University, Jingzhou 434023, China

2 China Petroleum Technology and Development Corporation, Beijing 100028, China

3 Research Institute of Petroleum Exploration and Development, Beijing 100083, China montmorillonites which is mainly reflected in the water content is close to $20-30 \%$. The degree and speed of screen blocking can be reduced by reducing the water content of produced fluid.

Keywords Water contents $\cdot$ Montmorillonite $\cdot$ Sand control $\cdot$ Jamming $\cdot$ Inflation

\section{Introduction}

Clay minerals are ubiquitous in oil and gas reservoir, the main component of which are kaolinite, montmorillonite, illite and chlorite etc. Because of the different molecular structure, they have different physical and chemical properties (Xu et al. 1999). As the clay minerals have the characteristics of large surface, active chemical property and so on, the clay minerals would contact with the fluid in stratum after the reservoir is opened, and the physical parameters of the reservoir rock are significantly changed, such as the change of wettability, permeability and pore structure (Kang and Luo 2000). For the reservoir, sandstone and siltstone are mainly reservoirs (Chen et al. 2013), and mudstone and shale are separation layers. For the research of expansion characteristics of clay minerals, Fancher through the experiments found that the air permeability of rock samples is not consistent with the water permeability; Then, Jhonson and eBeson further confirmed the above phenomenon, and they also found that the permeability of rock measured in freshwater and salty water is not the same. The main work before $1960 \mathrm{~s}$ is verifying the water sensitivity of sandstone (Kang and Luo 2000). In the later period, the main research is the effect of microparticles migration on the damage of reservoir (Ju et al. 2003), which is mainly used in reservoir protection and analysis of 
drilling fluid (Lou et al. 1989; Cai et al. 2001). In the process of production, the screen is easy to be blocked by the sand in stratum (Wang et al. 2000; Dong et al. 2011). If the water content of reservoir increased, the montmorillonite in clay minerals would swell, which combined with formation sand has an obvious effect on the plugging of screen pipe in production string (Zhang and Qu 2001). This paper utilizes shale expansion instrument to establish the relationship between the different water content and swelling properties of montmorillonites based on the prediction of water production of reservoir and utilizes sand control test equipment to carry out the plugging test of screen under different water content to evaluate the blocking effect of clay mineral content especially the content of montmorillonite on the plugging of screen in the process of sand control.

\section{Research on the prediction of water production in stratum}

In the process of existing sand control, the water content of stratum is seldom considered. But in the early stage of production, the reservoir may produce water, if not in early stage, the reservoir would produce water in the late stage of production. The prediction of the water content and the judgment of the aquifer in the field are mainly used as the principle of formation evaluation to determine the characteristics and logging response of water-yielding stratum and then qualitatively identify the water-yielding stratum (Liu and Xia 1998). Different logging information has different response characteristics to the physical properties and properties of fluid contented in reservoir. Through the comprehensive analysis of these differences, oil-bearing ability, movable hydrocarbon, movable water of reservoir can be evaluated, and the fluid property of reservoir also can be determined. Through comparing the applicability and accuracy, the main method which is commonly used to identify the water-yielding stratum is ordinary resistivity method, deep and shallow resistivity difference ratio method, acoustic electric intersection method and acoustic electric difference method.

The prediction of formation water is mainly based on the theory of percolation mechanics, and the production formula for the plane radial flow of single well is as follows (Luo et al. 2007).

$\frac{Q}{h}=\frac{2 \pi K\left(P_{e}-P_{w}\right)}{\mu \ln \frac{R_{e}}{R_{w}}}$

where $Q$ is the water production of stratum, $\mathrm{m}^{3} / \mathrm{s}$. $\mathrm{h}$ is the thickness of water-yielding stratum, m. $P_{e}$ is the pressure of water-yielding stratum, $\mathrm{Pa} . P_{w}$ is the bottom hole flowing pressure, $\mathrm{Pa} . R_{e}$ is the supply radius of stratum produced water, m. $R_{w}$ is the radius of borehole, m. $K$ is permeability, $\times 10^{-3} \mu \mathrm{m}^{2} . \mu$ is the viscosity of water in stratum.

In short, utilize logging data to calculate the water production of stratum before and after drilling can quantitatively predict the water production, which has a great significance to the evaluation of sand control method in the process of well completion.

\section{Experimental study on the effect of water content on swelling of montmorillonite}

\section{Experimental device}

In order to test the swelling behavior of montmorillonite, shale expansion instrument is mainly utilized for analysis (Zhao et al. 1996), and the shale expansion instrument contains four parts which are mechanical measuring system, displacement transducer, measuring instrument, data processing and storage device ( $\mathrm{Li}$ and $\mathrm{Li}$ 1995). The shale expansion instrument is shown in the left of Fig. 1. The main content of the experiment is pressing the pure montmorillonite into artificial core samples which can simulate natural core to a certain extent. Then, place the core samples into the solution of finishing agent, due to hydration which may cause shale swelling, the sample will absorb water and swell slowly with time passed, the expansion of sample can be measured by measurement system.

\section{Experimental procedure and method}

The test method followed China national standard "rock physical and mechanical properties test procedures Part 10: rock swelling test“" (DZ/T 0276.10 2015).

1. Get $2 \mathrm{~g}$ pure montmorillonite with a scale, as shown in the right of Fig. 1, and put it into test cup, then place the assembled test cup on the platform of press machine, set the working pressure to $4 \mathrm{MPa}$ and maintain this constant pressure for $5 \mathrm{~min}$.

2. Install the test cup and test rod, then adjust and calibrate test instrument.

3. Mixing oil and water (white oil and simulated formation water with a certain degree of mineralization) by volume ratio, then drop the solution into the test cup, start the test when the solution filled test cup and complete the test if the measurement is a constant.

\section{Montmorillonite swelling test}

The experiment mainly uses the industrial pure bentonite to analyze the expansion of montmorillonite, the viscosity of simulated oil is $20 \mathrm{mpas}$ and the mineralization of 
Fig. 1 Montmorillonite swelling test device (left) and montmorillonite (right)
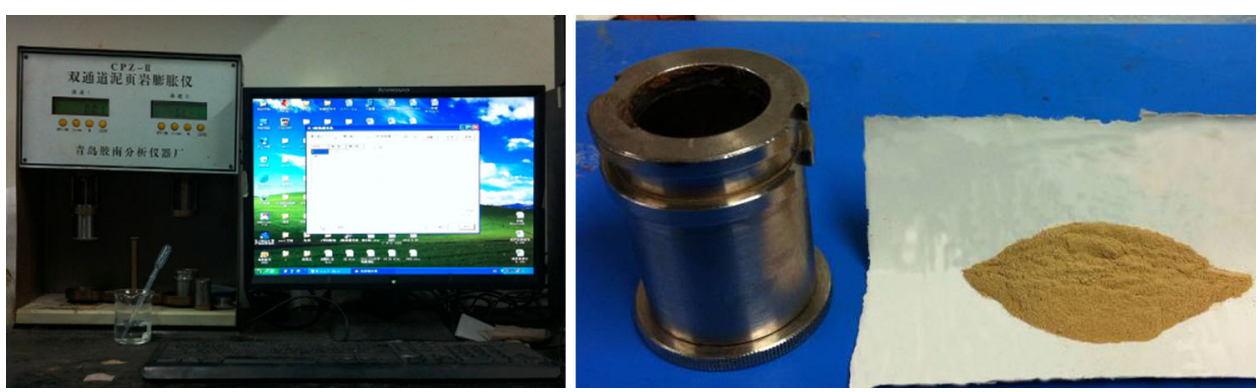

simulated formation water is $3000 \mathrm{mg} / \mathrm{L}$. By means of measurement and calculation, the initial thickness of compacted montmorillonite sample is $1.79 \mathrm{~mm}$, and then the expansion characteristics of montmorillonite were analyzed under different water content. Clay swelling is the result of hydration of montmorillonite in clay. In the process of analysis, the swelling properties of montmorillonite were determined by the measured linear expansion of montmorillonite (called the expansion rate), the formula as follows.

$\lambda=\frac{h_{t}}{h} \times 100 \%$

where

$\lambda$ is the linear expansion rate of montmorillonite at time of $t, \% . h_{t}$ is the linear expansion of montmorillonite at time of $t, \mathrm{~mm} . h$ is the initial thickness of compacted montmorillonite sample.

As shown in Fig. 2, when the water content is less than $10 \%$, the difference of the expansion height is small; when the water content is more than $20 \%$, the difference of the expansion height is also small. When the water content is between 20 and $10 \%$, the difference of the expansion height is also large, which change from $0.6 \mathrm{~mm}$ to $1.6 \mathrm{~mm}$, expansion height increased by nearly two times and its expansion rate reach to $188 \%$. It means that the water content of stratum between 10 and 20\% has a big influence on the swelling of montmorillonite in clay mineral, and it also would affect the production after sand control.

\section{Experimental study on the effect of water content on the blocking of sand control screen}

\section{Optimization selection principle of screen}

A series of comparative evaluation tests were completed by the sand control simulation test device of China University of Petroleum (Beijing) (Deng et al. 2012). The test equipment based on the full size sand pipe, diaphragm pump, safety valve and a series of equipment was utilized to simulate stable production conditions of oil-water mixture and carried out the regular evaluation test of radial flow of oil-sand mixture in wellbore with confining pressure, which would be better to evaluate the effect of formation conditions on the production of screen. In order to evaluate the performance of sand control screen in the process of simulated production, and the same for the actual production of oil fields, which means to seek a kind of sand control method that is suitable for the long-term development of the oil fields, the principle of improving the capacity as much as possible under the premise of
Fig. 2 Swelling ratio of montmorillonite under different water content

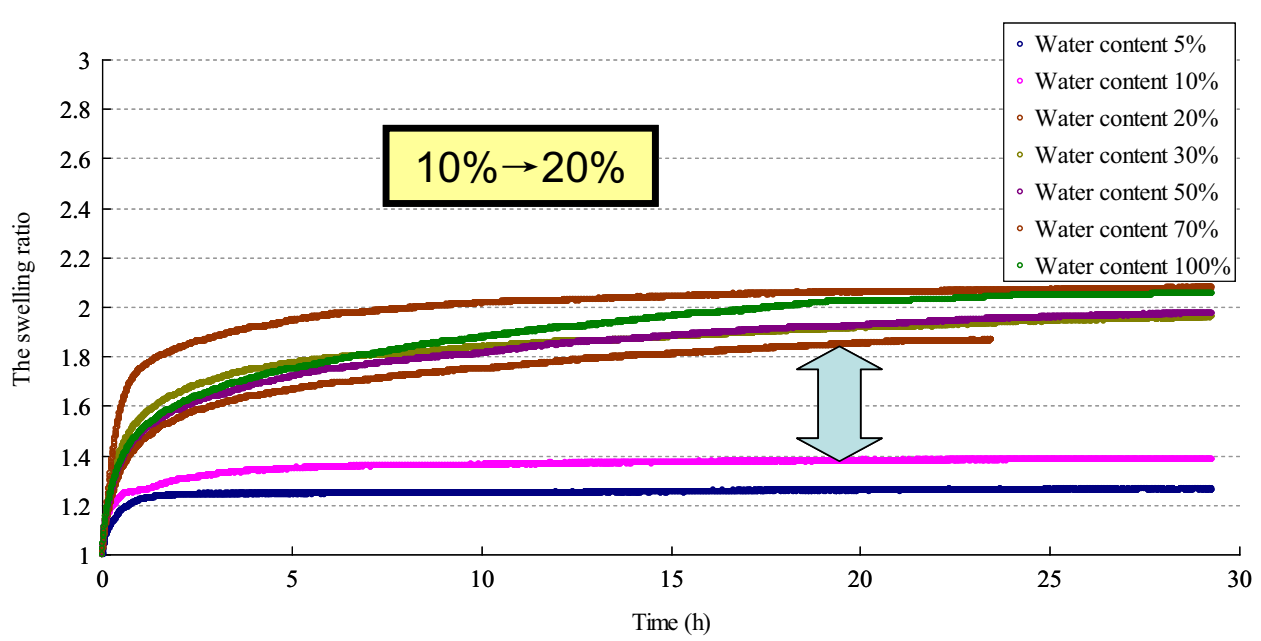

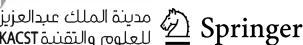


ensuring the effect of sand control is put forward which can balance the contradiction between sand control and production. Therefore, it is needed to study the change rule of sand production and productivity under different sand control methods. The production can be defined by the productivity index per meter (Deng et al. 2011), as shown in formula (3).

$J=\frac{Q}{\left(p_{e}-p_{\mathrm{wf}}\right) h}$

where $J$ is productivity index per meter, $\mathrm{m}^{3} /$ $(\mathrm{m} \times \mathrm{d} \times \mathrm{MPa}) . Q$ is flowrate, $\mathrm{m}^{3} / \mathrm{d} . h$ is effective flow length of sand control pipe, m. $P_{e}$ is reservoir pressure, MPa. $P_{\mathrm{wf}}$ is gas pressure at the bottom of the well, MPa.

\section{Comparative test study on the sand control of screen under different water content}

In the design of sand control, the content of clay minerals has important significance for the selection of sand control methods, the hydration swelling of montmorillonite in clay minerals would block the hole of screen easily and reduce the production of oil well in later stage of production. In the experiment, six kinds of water content were set for analysis, including 0, 10, 20, 30, 50, 70 and $100 \%$. So, the evaluation comparable testing of the effect of different water content on the sand control performance of screen was carried out based on these six kinds of water content. According to the stratigraphic characteristics of Bohai Bay, set the particle size sample and shale content sample, median particle size $\mathrm{UC}=5-10$, $\mathrm{d} 50=150 \mathrm{~mm}$, ratio of mixed sand is $6 \%$, the sand of test formation is industry standard mesh quartz sand. According to the established sample database, calculate the characteristic value of particle size and then adjust the proportion of different mesh quartz sand to make the characteristic value of particle size of prepared quartz sand consistent with reservoir. In the experiment, the length of metal mesh screen is $35 \mathrm{~cm}$, the accuracy of the screen is $150 \mu \mathrm{m}$, the viscosity of oil sample is $20 \mathrm{mpa} \mathrm{s}$, the density of oil sample is $0.9 \mathrm{~g} / \mathrm{cm}^{3}$, and mineralization degree is $3000 \mathrm{mg} / \mathrm{L}$, the content of montmorillonite is $20 \%$. The screen before and after the experiment is shown in Fig. 3.

The results in Fig. 4 show that the productivity index per meter of pre-graved screen simulated experiment decreased with the increase in experimental time under these six kinds of water content. At the same time, it also shows that the productivity index per meter of six groups experiment is relatively high in the early stage of simulation experiment, along with the experiment, the screen blocked fastest which only needs $7 \mathrm{~min}$ when the water content is 30 and $10 \%$, and the productivity index per meter is the lowest. If there is no water in the process of production, the screen needs $20 \mathrm{~min}$ to be blocked, the speed is relatively lower compared to the former close to three times, the speed of which is reduced by nearly three times compared to the former. In terms of flow, when the water content is $100 \%$, the productivity index per meter is $30 \mathrm{~m}^{3} / \mathrm{d} \times \mathrm{m} \times \mathrm{MPa}$, compared to the productivity index per meter when water content is 30 and $10 \%$, the difference between the two values is very large. Because the viscosity of water is much lower than oil, and the water content is 0 in the early stage of oil production, the productivity index is large which is higher than the value under the condition of low water content. The relative permeability of oil and water is related to the ratio of viscosity of water and oil, when the water content continues to increase, the corresponding productivity index per meter increased. As the result shown in Fig. 5, it shows that the ratio of water and oil has a greater effect on the productivity index per meter of metal mesh screen than the swelling of montmorillonite. When the water content is nearly between 30 and $20 \%$, the expansion of clay increased dramatically, which has the most influence on the rice production index in the process of production, which has a decisive role in the selection of sand control method.

\section{Conclusions}

1 From the test of the swelling of montmorillonite with different moisture content, we found 1 . The expansion experiment of montmorillonite under different water content was carried out, it is found that the difference of the expansion height is small when the water content is below 10 and above $20 \%$. When the water content is between 10 and $20 \%$, the maximum swelling height of montmorillonite is greatly changed from $0.6 \mathrm{~mm}$ to $1.6 \mathrm{~mm}$, and the height of expansion is increased by nearly two times.

2 For the productivity index per meter of metal mesh screen, the effect of ratio of water and oil is greater than the swelling of montmorillonite. When the water content is close to $30-20 \%$, which has a big influence on the productivity index per meter in the process of production, it has a decisive role in the selection of sand control method.

3 It is necessary to control the water content of the production in the production process, which can increase the recovery rate in the process of production, and it is helpful for reducing the blocking of screen and increasing the production in the late stage of production. That there is little difference of the expansion height between the water content is lower than $10 \%$ and higher than $20 \%$. Between 
Fig. 3 Screen contrasted before and after the experiment under different water content
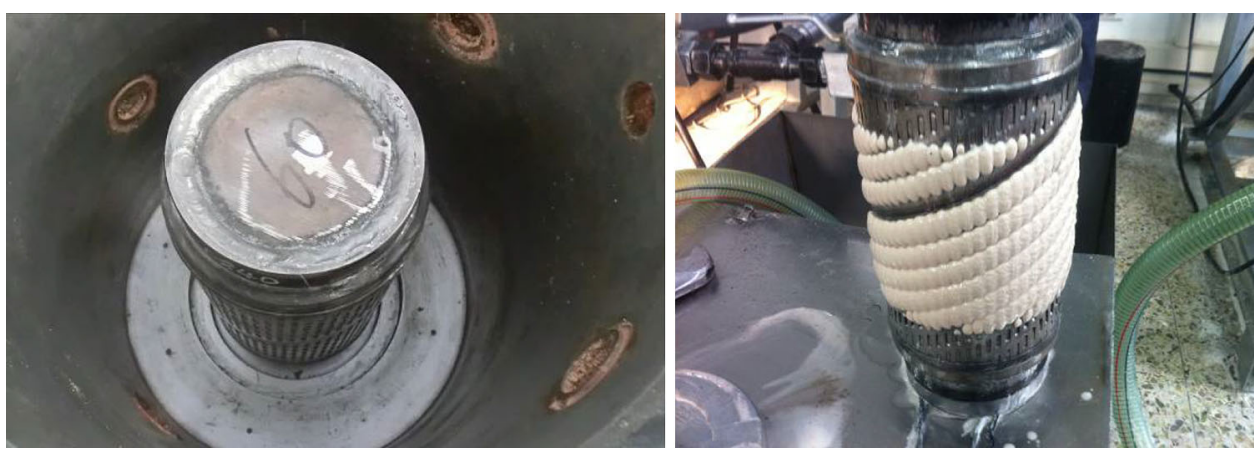

Fig. 4 Curves of productivity index per meter under different water content

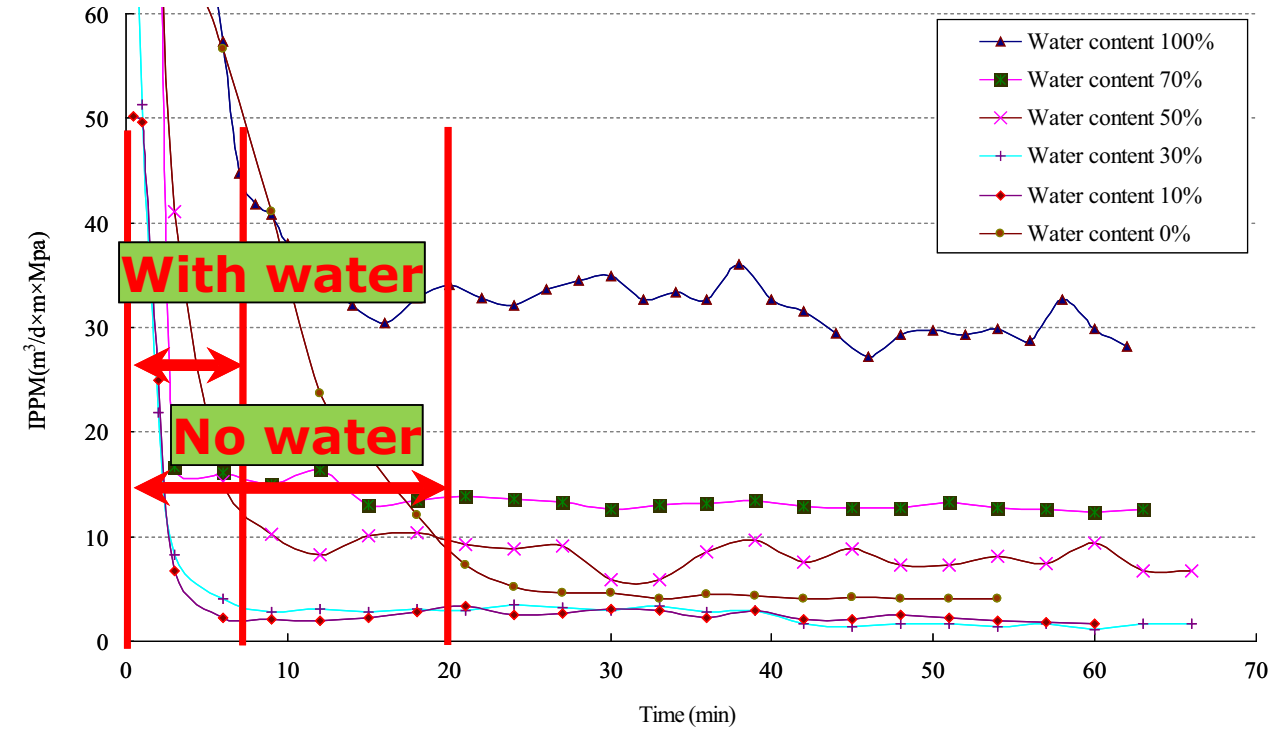

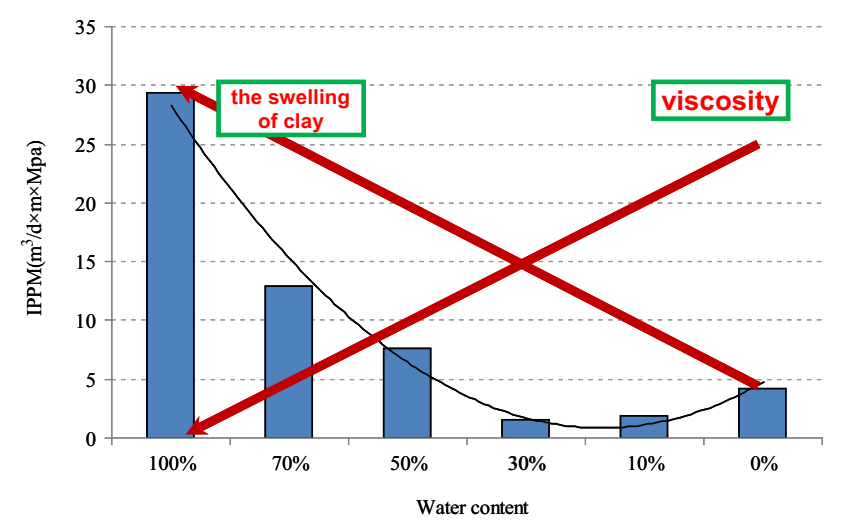

Fig. 5 Comparison chart of productivity index per meter under different water content

10 and $20 \%$ of water content, the swelling height of montmorillonite changed greatly, the maximum height of the expansion was from $0.6 \mathrm{~mm}$ to $1.6 \mathrm{~mm}$, which increased more than two times.

Acknowledgements This paper was supported by the Yangtze Youth Fund (Grant No. 2015cqn43), the National Natural Science Foundation of China (Grant No. 51504040).
Open Access This article is distributed under the terms of the Creative Commons Attribution 4.0 International License (http:// creativecommons.org/licenses/by/4.0/), which permits unrestricted use, distribution, and reproduction in any medium, provided you give appropriate credit to the original author(s) and the source, provide a link to the Creative Commons license, and indicate if changes were made.

\section{References}

Cai JG, Zhang S, Xie Z et al (2001) Sandstone diagenesis and formation damage prevention in shengli oildom. J China Univ Pet 4:13-15

Chen KS, Chong D, Masoudi R, et al (2013)Production integrated sand control benchmark for field development [J]. IPTC 16449

Deng J, Li P, Wang L et al (2011) The optimization of sand control method for moderate sand control technique application in Bohai Bay. Oil Drill Prod Technol 33(1):98-101

Dong C, Jia B, Liu C et al (2011) Blocking mechanism and blocking laws experiments of sand retention media in mechanical screens. J China Univ Pet 35(5):82-88

Deng J, Li P, Zhou J et al (2012) Sand control optimization applied to moderately sanding wells in offshore loose sandstone reservoirs. Acta Pet Sin 33(4):676-680 
Ju B, Ma M, Qiu X (2003) The mathematical simulation method of migration of fines and clay swell in elastic porous medium. J Hydrodyn 1:8-15

Kang Y, Luo P (2000) Influence of clay minerals on formation damage in sandstone reservoir: a review and prospect in it. Drill Fluid Complet Fluid 5:39-43

Li W, Li X (1995) Effect of fluoboric acid and mud acid on clay swelling property. Oil Drill Prod Technol 2:56-60

Liu X, Xia H (1998) The effect of water sensitive hydrated shale formation on $\log$ response. Drill Fluid Complet Fluid. 4:8-11

Lou L, Zhao X, Wang J (1989) A study of the damage of clay minerals to oil and gas bearing formations and the antiexpansion agents. Atural Gas Ind 1:29-34

Luo R, Cheng L, Peng J et al (2007) A new method of determining relationship between permeability and effective overburden pressure for low-permeability reservoirs. J China Univ Pet 2:87-90

Wang Z, Li A, Zhang $\mathrm{H}$ et al (2000) Experimental study on poreblocking mechanism in gravel packs of sand control well. J China Univ Pet 5:49-51

Xu Q, Wang S, Hu S et al (1999) The numerical method for estimating the effect of clay swelling and fines migration on permeability. Drill Fluid Complet Fluid 5:4-6

Zhang J, Qu Y (2001) Research on the expansive soils in Three-Gorge Reservoir region. Chin J Geotech Eng 23(6):724-727

Zhao X, Zhu M, Xie B et al (1996) Drilling and completion fluid weighted with water-soluble salt grains. J China Univ Pet 4:34-39 